\title{
Effect of sodium butyrate and Yucca schidigera extract on bone characteristics in growing pigs
}

\author{
Iwona Puzio ${ }^{1}$, Jose Luis Valverde Piedra ${ }^{2}$, \\ Małgorzata Kapica ${ }^{1}$, Radosław P. Radzki ${ }^{1}$, Marek Bieńko ${ }^{1}$, \\ Marta Pawłowska ${ }^{1}$, Sylwia Szymańczyk ${ }^{1}$ \\ ${ }^{1}$ Department of Animal Physiology \\ ${ }^{2}$ Department of Veterinary Preclinical Sciences, Sub-Department of Toxicology and Environmental Protection, \\ Faculty of Veterinary Medicine, \\ University of Life Sciences in Lublin, 20-950 Lublin \\ iwona.puzio@up.lublin.pl
}

Received: December 9, 2015 Accepted: March 11, 2016

\begin{abstract}
Introduction: The aim of this study was to investigate the influence of diet supplementation with sodium butyrate and Yucca schidigera extract $(0.2 \%$ and $0.3 \%)$ on femur quality of growing pigs $(n=45)$. Material and Methods: At the age of 28 , 35 and $56 \mathrm{~d}$, five piglets from each group fed a different diet were euthanised and the femora were collected for further analyses. The bone characteristics were assessed based on weight, length, densitometric analysis of BMC and BMD, pQCT analysis (area, mineral content, volumetric density of trabecular and cortical part of metaphysis and diaphysis, respectively), ultimate strength, and geometrical parameters (cross-sectional area and second moment of inertia). Results: There were no significant differences in femur bone parameters among experimental groups on the $28^{\text {th }} \mathrm{d}$ of life. On the $35^{\text {th }} \mathrm{d}$ of life, piglets with $0.2 \%$ supplementation of sodium butyrate and Yucca schidigera extract had significantly lower values of weight and second moment of inertia, and significantly higher trabecular BMD and BMC compared to other experimental groups. In 56-day-old pigs, the higher values were observed in both experimental groups regarding BMC, ultimate strength, geometrical parameters, cortical BMC, diaphyseal total area, and endosteal circumference $(\mathrm{P}<0.05)$. Significant differences between experimental groups were observed only in bone weight and cortical thickness. Conclusion: This study proved that simultaneous supplementation with sodium butyrate and Yucca schidigera extract positively influences bone quality in pigs in the post-weaning period. However, there were no differences in bone characteristics between the addition of $0.2 \%$ and $0.3 \%$ preparations.
\end{abstract}

Keywords: pig, bone development, sodium butyrate, Yucca schidigera.

\section{Introduction}

Maximising farm productivity has led to weaning animals at an earlier age. However, one must remember that the process of weaning, i.e. piglets involves the transition from mother's milk to solid feed, changes in housing environment, and requires adaptation of the gastrointestinal system. These changes are often associated with proliferation of pathogens in the digestive tract, resulting in diarrhoea and compromised performance. In consequence, the need to utilise more efficiently acting ingredients in the diets for earlyweaned animals, which protect microflora of the gastrointestinal tract (GIT) to avoid scouring and improve performance, has encouraged the development of alternative feed additives. Especially, the ban on the use of antibiotics in EU countries in 2006 stimulated a great number of studies on the use of alternative substances, such as probiotics, acidifiers, herb extracts, enzyme cocktails, non-digestible oligosaccharides with or without prebiotic properties, and others $(10,14,16$, $30,32)$. Among the currently available alternatives that might substitute antibiotics as growth promoters in diets for young pigs, organic acids are one of the most promising. Most studies have been conducted using formic, lactic, citric, and other acids $(16,22)$. In the last few years, beneficial effects of short-chain fatty acids (SCFAs) were confirmed in pigs $(12,16)$ and in laying 
hens (28). The results of several studies on rats (15) and pigs (22) have shown that reducing the gastrointestinal $\mathrm{pH}$ due to addition of organic acids to the diet increases calcium absorption and retention, which may be of great importance for bone metabolism.

SCFAs are the main end products of bacterial fermentation (metabolism of dietary fibre) in the large intestine, and the main source of anions in the hind gut in monogastric animals; they can also be used as energy supply for the epithelial cells of gut mucosa (21). Among SCFAs, butyrate is considered to be the most effective for promoting epithelial growth (42) and sodium and water absorption (7). Sodium butyrate (SB) was found to have an antiproliferative and differentiation-inducing activity on various normal cells, human colon carcinoma cells, and neoplastic cells (38). Moreover, the inhibitory effect of butyrate on tumour development has been discussed (24).

Nowadays, plant extracts used in animal production present antimicrobial, antiviral, antitoxin, and antioxidant effects. They can also stimulate digestive enzymes' activity and nutrients' absorption (16). Yucca schidigera extract is currently used in a number of applications. The positive effects of Yucca schidigera in livestock and poultry production result in increased growth rate and improved feed conversion efficiency, reduction of ammonia production in the GIT and faecal odours in animal excreta, anti-protozoal and nematocidal activity, modification of microbial populations in the GIT, and reduction of cholesterol content in eggs and tissues $(1,20,33)$. Other research studies suggest a possible role of yucca extract components in preventing arthritis by antiinflammatory activity (2).

Modern pig production is based on animals selected for rapid growth, large muscle mass achievement, and efficient feed conversion. Under these conditions of intensive methods of production and stress much greater strength and effectiveness of the bone development are absolutely essential. Taking into account that sodium butyrate positively influences nutrients digestion, absorption area, and integrity of the small intestine $(5,10)$, stimulates osteoblast differentiation, and promotes bone regeneration (36); thus it can be assumed that dietary sodium butyrate supplementation may be helpful in preventing problems of growth and mineralisation of bones in post-weaning period. However, one should also take into consideration the fact that butyrate influences osteoclast formation and differentiation (3), and in this way it can stimulate osteoclastogenesis and osteoclast activity. On the other hand, Yucca schidigera contains substances that enhance nutrients absorption and potentially affect bone metabolism.

In our previous study we concluded that sodium butyrate and Yucca schidigera extract may be useful in feeding growing pigs (30). Early postnatal treatment of pigs with sodium butyrate and Yucca schidigera extract positively affected the features of bones in 56-day-old piglets, but not in younger animals (26). However, except our research, there is no other data in the literature on simultaneous effect of sodium butyrate and Yucca schidigera extract dietary supplementation on bone parameters. Moreover, further studies are needed to verify our hypothesis about the positive effects of these supplements on bones in order to determine whether the level of supplementation influences growth and characteristics of bones.

Thus, the aim of this study was to investigate the influence of the level of sodium butyrate and Yucca schidigera extract on mineral density, mineral content, and geometric features of the femur bone in growing pigs.

\section{Material and Methods}

Experimental design, animals, diets. The study was performed on Polish Large White $\mathrm{x}$ Petrain crossbreed piglets of both sexes from the $14^{\text {th }}$ until $56^{\text {th }}$ day of their postnatal life. During the whole period of the study the piglets were housed indoors in pens under identical farm conditions. Until weaning ( $28 \mathrm{~d})$, the animals were kept with sows. On the $14^{\text {th }}$ day of age, the piglets were divided into three groups fed an appropriate diet for each developing period; 15 piglets from two litters were assigned to control group (C) and 30 piglets from four litters were assigned to experimental groups: E1 and E2. Every group received creep feed (M1) in a fodder for each litter from the $14^{\text {th }}$ to $28^{\text {th }}$ day of life. The piglets were weaned on the $28^{\text {th }}$ day of life and allocated according to group treatment. From $29^{\text {th }}$ to $42^{\text {nd }}$ day of life, post-weaning piglets were fed the M2 diet, and from the $43^{\text {rd }}$ to the $56^{\text {th }}$ day of life received the M3 diet (Table 1). Control piglets received a diet with the addition of protective organic acids ( $3 \mathrm{~kg} / \mathrm{t}$ of feed), while the piglets from the experimental groups received the same acids and additionally sodium butyrate (Soda Feed Ingredients, Monaco) and Yucca schidigera extract (Ultra Bio-Logics, Mexico) (Table 2). The feed additives were administered at the level of $2 \mathrm{~kg} / \mathrm{t}$ of feed (E1 group) and $3 \mathrm{~kg} / \mathrm{t}$ of feed (E2 group) from the $14^{\text {th }}$ to $42^{\text {nd }}$ day of life, and then $2 \mathrm{~kg} / \mathrm{t}$ of feed from the $43^{\text {rd }}$ to $56^{\text {th }}$ day of life.

Sample collection and analysis. For studying the influence of sodium butyrate and Yucca schidigera extract on the bone development and their characteristic at the age of 28,35 and 56 days, the piglets were weighed and five piglets from each group were chosen (two with the lowest weight, two with the highest and one medium weight), and euthanised by administration of sodium pentobarbital overdose (20 mg/kg b.w.). Next, the left femora were isolated, stripped from soft tissues, and their weight and length were measured. The bone samples were frozen at $-25^{\circ} \mathrm{C}$ and maintained for further analysis. 
Table 1. Components and calculated composition of the feed mixtures (M1, M2, M3) applied in control and experimental pigs from the $14^{\text {th }}$ to the $56^{\text {th }} \mathrm{d}$ of age

\begin{tabular}{|c|c|c|c|}
\hline Item & $\begin{array}{l}\text { M1 } \\
(14-28 \mathrm{~d})\end{array}$ & $\begin{array}{l}\text { M2 } \\
(29-42 d)\end{array}$ & $\begin{array}{l}\text { M3 } \\
(43-56 d)\end{array}$ \\
\hline \multicolumn{4}{|l|}{ Ingredients (\%) } \\
\hline Corn & 25.0 & 15 & 15.0 \\
\hline Wheat & $29.025 / 28.925$ & $43.065 / 42.965$ & $42.055 / 41.955$ \\
\hline Barley & 10.0 & 25.0 & 25.0 \\
\hline Solvent-extracted toasted soybean meal $46 \%$ & 7.2 & 7.2 & 12.6 \\
\hline Soya oil & 8.0 & 0.5 & 0.5 \\
\hline Milk compounds (Portilac) & 10.0 & 1.0 & - \\
\hline Yeast & 5.0 & 3.0 & - \\
\hline Monocalcium phosphate & 0.9 & 0.42 & 0.41 \\
\hline Calcium carbonate & 1.4 & 0.9 & 0.9 \\
\hline Protein concentrate & 1.0 & 1.0 & 1.0 \\
\hline Premix 0.2 phytase & 0.25 & 0.2 & 0.2 \\
\hline L-lysine $\mathrm{HCl}$ & 0.57 & 0.71 & 0.64 \\
\hline DL-methionine & 0.70 & 0.55 & 0.52 \\
\hline L-threonine & 0.38 & 0.36 & 0.23 \\
\hline L-tryptophan & - & 0.2 & 0.02 \\
\hline Choline chloride & 0.02 & 0.02 & 0.05 \\
\hline Rovabio excel AP & 0.005 & 0.005 & 0.005 \\
\hline Feed additive & $0.2 / 0.3$ & $0.2 / 0.3$ & $0.2 / 0.3$ \\
\hline Vitamin blend & 0.3 & 0.15 & 0.15 \\
\hline Mineral blend & 0.05 & 0.05 & 0.05 \\
\hline $\mathrm{NaCl}$ & - & 0.47 & 0.47 \\
\hline \multicolumn{4}{|l|}{ Calculated composition (\%) } \\
\hline Energy, MJ & 15.4 & 13 & 13 \\
\hline Fat & 10.3 & 3.0 & 3.0 \\
\hline Protein & 19.2 & 16.5 & 16.0 \\
\hline Fibre & 2.2 & 4.0 & 4.0 \\
\hline Lactose & 10.0 & - & - \\
\hline Ash & 4.0 & 7.0 & 6.0 \\
\hline Calcium & 1.0 & 0.65 & 0.65 \\
\hline Phosphorus & 0.6 & 0.50 & 0.50 \\
\hline Sodium & 0.1 & 0.20 & 0.20 \\
\hline Lysine & 1.4 & 1.25 & 1.15 \\
\hline Methionine & 1.0 & 0.8 & 0.75 \\
\hline Threonine & 0.9 & 0.8 & 0.75 \\
\hline Tryptophan & 0.2 & 0.2 & 0.20 \\
\hline
\end{tabular}

Vitamin blend: vitamin A - $24375 \mathrm{IU}$, vitamin $\mathrm{D}_{3}-3875 \mathrm{IU}$, vitamin E - $165.5 \mathrm{mg}$, vitamin $\mathrm{K}-7.625 \mathrm{mg}$, vitamin $\mathrm{B}_{1}-13.963$ $\mathrm{mg}$, vitamin $\mathrm{B}_{2}-12.25 \mathrm{mg}$, vitamin $\mathrm{B}_{6}-5.163 \mathrm{mg}$, vitamin $\mathrm{B}_{12}-255.0 \mu \mathrm{g}$, biotin $-94.0 \mu \mathrm{g}$, folic acid - $1.775 \mathrm{mg}$, nicotinic acid $48.75 \mathrm{mg}$, pantothenic acid - $36.0 \mathrm{mg}$, choline chloride - $340.0 \mathrm{mg}$; mineral blend: magnesium - $0.113 \%$, chlorine - $0.221 \%$, potassium - $0.606 \%$, iron - $152.5 \mathrm{mg}$, zinc - $149.25 \mathrm{mg}$, manganese - $85.25 \mathrm{mg}$, copper - $27.75 \mathrm{mg}$, iodine - $1.354 \mathrm{mg}$, selenium $0.435 \mathrm{mg}$

Table 2. Composition of the feed additive preparation used in the control and experimental diet

\begin{tabular}{lll}
\hline Item & Control & E1, E 2 \\
Sodium butyrate, \% & - & 30 \\
Fumaric acid, \% & 10 & 10 \\
Malic acid, \% & 5 & 5 \\
Citric acid, \% & 5 & 5 \\
Yucca schidigera extract, \% & - & 2.5 \\
Triglycerides from vegetal origin, \% & ad 100 & ad 100 \\
\hline
\end{tabular}

Before analyses the bones were thawed at room temperature for $12 \mathrm{~h}$ prior to use. Bone mineral density (BMD) and bone mineral content (BMC) were measured using Dual X-ray Absorptiometry (DXA). The measurements were performed on the Norland Excell Plus X-ray densitometer (Fort Atkinson, USA) using special software for investigation of bones from various type of animals (Small Subjects Scan version 3.9.6). The measurements of whole bone BMC and the areal BMD were performed using the following parameters: scout scan speed $260 \mathrm{~mm} / \mathrm{s}$, resolution
$3.0 \times 3.0 \mathrm{~mm}$; measurement scan speed $30 \mathrm{~mm} / \mathrm{s}$, resolution $1.0 \times 1.0 \mathrm{~mm}$. Scanning orientation was an anterior-posterior plane (direction) and each bone was scanned separately. A quality assurance test to verify the stability of the system calibration was performed on a daily basis as indicated by the manufacturer.

The femora were scanned in the place corresponding to $18 \%$ of bone length from the distal end and in the middle diaphysis with a peripheral quantitative computed tomography (pQCT) XCT Research SA Plus system, using software version 5.5 D 
(Stratec Medizintechnik GmbH). The scans were performed in the distal metaphysis for analysis of the trabecular bone tissue and in the middle diaphysis for the analysis of the cortical bone tissue. Upon completion of scanning, the following parameters were determined: total bone area (tA), cortical area (CtA), cortical bone mineral content (CtBMC), cortical bone density (CtBMD), cortical thickness (CtT), trabecular area ( $\mathrm{TbA})$, trabecular bone mineral content (TbBMC), trabecular bone density (TbBMD), total bone mineral content (tBMC), total bone mineral density (tBMD), periosteal circumference (PERI.C), endosteal circumference (ENDO.C), and bone strength index (BSI).

Ultimate strength (Wf) of bones was measured by three-point bending test using an INSTRON 4302 apparatus (Instron Corp., USA) linked to a computer, registering the relationship between the perpendicular force acting to the longitudinal axis of the bone and the resulting displacement (6). The distance between supports was set at $40 \%$ of the bone length. On the basis of vertical and horizontal diameters of the bone mid-shaft cross section, the geometrical parameters such as the cross-sectional area (A) and second moment of inertia (Ix) were determined as described previously (6).

Statistical analysis. All data are presented as mean \pm SD. Statistical analysis was performed using Statistica 6.0 software. Differences between means were tested with the use of a Tukey's multiple comparison test. Significant difference among the treatments was shown as $\mathrm{P}<0.05$.

\section{Results}

No significant differences in the body weight between the groups at the respective age of pigs (data not shown) were found. There were no significant differences in femur parameters among the groups in 28-day-old piglets (Tables 3 and 4). On the $35^{\text {th }}$ day of life, the pigs which were given mix of organic acids and Yucca schidigera extract at the level of $0.2 \%$ showed a tendency to decreased bone weight, length, BMC, BMD, ultimate strength, second moment of inertia, and cross-sectional area (Table 3). The statistically significant differences between group E1 and group $\mathrm{C}$ were observed in weight, length, and cross-sectional area, and between groups E1 and E2 in weight and second moment of inertia. The length, BMC, BMD, ultimate strength, and cross-sectional area of the group E1 did not differ significantly from the values obtained in the group E2 (Table 3). There were no significant differences in quantitative computed tomography parameters for cortical bone between control and experimental groups in 35-day-old pigs (Table 4). However, the bones of pigs in group E1 had significantly higher values of TbBMD and TbBMC compared to those in group C and group E2.

Supplementation with sodium butyrate and Yucca schidigera extract from the $14^{\text {th }}$ to $56^{\text {th }} \mathrm{d}$ of life significantly increased BMC, ultimate strength, and geometrical parameters of the femur compared with controls (Table 3). The higher values in both experimental groups were also observed in bone weight and BMD. Sodium butyrate and Yucca schidigera extract resulted in a significantly greater femur CtBMC, diaphyseal tA, and ENDO.C in both experimental groups compared with control group (Table 4). Supplementation with the compounds at the level of $0.2 \%$ during whole experimental period significantly increased the PERI.C, CtT, and BSI values compared with the group C. Significant differences between groups E1 and E2 were observed only for bone weight and cortical thickness (Tables 3 and 4).

Table 3. Effect of dietary supplementation with sodium butyrate and Yucca schidigera extract on femur properties ( $\mathrm{n}=5$ in each group)

\begin{tabular}{|c|c|c|c|c|c|c|c|c|c|}
\hline \multirow{2}{*}{ Parameters } & \multicolumn{3}{|c|}{$28 \mathrm{~d}$} & \multicolumn{3}{|c|}{$35 \mathrm{~d}$} & \multicolumn{3}{|c|}{$56 \mathrm{~d}$} \\
\hline & $\mathrm{C}$ & E1 & E2 & $\mathrm{C}$ & E1 & E2 & $\mathrm{C}$ & E1 & E2 \\
\hline Weight (g) & $38.0 \pm 2.74$ & $33.0 \pm 1.77$ & $35.0 \pm 0.77$ & $44.0 \pm 2.76^{\mathrm{a}}$ & $35.0 \pm 1.36^{b}$ & $42.0 \pm 2.45^{\mathrm{a}}$ & $74.0 \pm 4.67^{\mathrm{a}}$ & $89.0 \pm 5.41^{b}$ & $77.0 \pm 2.00^{\mathrm{a}}$ \\
\hline Length (mm) & $90.0 \pm 2.46$ & $83.0 \pm 1.82$ & $88.0 \pm 0.81$ & $97.0 \pm 2.87^{\mathrm{a}}$ & $88.0 \pm 2.03^{b}$ & $95.0 \pm 7.89^{\mathrm{ab}}$ & $116 \pm 2.60$ & $119 \pm 1.60$ & $116 \pm 2.82$ \\
\hline $\mathrm{BMC}(\mathrm{g})$ & $6.0 \pm 0.35$ & $6.0 \pm 0.60$ & $6.29 \pm 0.08$ & $7.87 \pm 0.78$ & $6.52 \pm 0.28$ & $7.14 \pm 0.43$ & $12.7 \pm 0.91^{\mathrm{a}}$ & $15.3 \pm 1.01^{\mathrm{b}}$ & $14.3 \pm 0.08^{\mathrm{b}}$ \\
\hline $\operatorname{BMD}\left(\mathrm{g} / \mathrm{cm}^{2}\right)$ & $0.35 \pm 0.01$ & $0.37 \pm 0.01$ & $0.34 \pm 0.01$ & $0.37 \pm 0.01$ & $0.36 \pm 0.01$ & $0.36 \pm 0.01$ & $0.42 \pm 0.01$ & $0.47 \pm 0.03$ & $0.48 \pm 0.01$ \\
\hline $\mathrm{Wf}(\mathrm{N} \cdot \mathrm{mm})$ & $1082 \pm 160$ & $972 \pm 126$ & $1106 \pm 102$ & $1302 \pm 69.0$ & $1117 \pm 76.0$ & $1328 \pm 331$ & $1514 \pm 123^{\mathrm{a}}$ & $1828 \pm 118^{b}$ & $2040 \pm 115^{\mathrm{b}}$ \\
\hline $\mathrm{Ix}\left(\mathrm{mm}^{4}\right)$ & $686 \pm 113$ & $719 \pm 64.0$ & $803 \pm 153$ & $879 \pm 140^{\mathrm{ab}}$ & $571 \pm 67.0^{\mathrm{a}}$ & $958 \pm 16.9^{b}$ & $1870 \pm 332^{\mathrm{a}}$ & $2968 \pm 394^{b}$ & $2475 \pm 177^{b}$ \\
\hline $\mathrm{A}\left(\mathrm{mm}^{2}\right)$ & $72.0 \pm 6.27$ & $76.0 \pm 5.11$ & $79.0 \pm 6.83$ & $82.0 \pm 4.99^{\mathrm{a}}$ & $66.0 \pm 5.75^{\mathrm{b}}$ & $89.0 \pm 3.93^{\mathrm{ab}}$ & $110 \pm 12.7^{\mathrm{a}}$ & $136 \pm 11.0^{\mathrm{b}}$ & $144 \pm 1.26^{\mathrm{b}}$ \\
\hline
\end{tabular}

a, b - means in rows with different superscripts differ significantly at the respective pig's age, $\mathrm{P}<0.05$; BMC - bone mineral content, BMD - bone mineral density, Wf - ultimate strength, Ix - second moment of inertia, A - cross-sectional area 
Table 4. Effect of dietary supplementation with sodium butyrate and Yucca schidigera extract on quantitative computed tomography parameters of femur diaphysis and metaphysis $(n=5$ in each group)

\begin{tabular}{|c|c|c|c|c|c|c|c|c|c|}
\hline \multirow{2}{*}{ Parameters } & \multicolumn{3}{|c|}{$28 \mathrm{~d}$} & \multicolumn{3}{|c|}{$35 \mathrm{~d}$} & \multicolumn{3}{|c|}{$56 \mathrm{~d}$} \\
\hline & $\mathrm{C}$ & E1 & E2 & $\mathrm{C}$ & E1 & E2 & $\mathrm{C}$ & E1 & $\mathrm{E} 2$ \\
\hline \multicolumn{10}{|l|}{ Diaphysis } \\
\hline $\operatorname{tBMD}\left(\mathrm{mg} / \mathrm{cm}^{3}\right)$ & $590 \pm 29.9$ & $617 \pm 23.7$ & $576 \pm 44.3$ & $634 \pm 18.8$ & $593 \pm 36.4$ & $572 \pm 11.2$ & $585 \pm 12.4$ & $548 \pm 21.1$ & $553 \pm 18.3$ \\
\hline $\mathrm{tBMC}(\mathrm{mg} / \mathrm{mm})$ & $63.0 \pm 2.87$ & $54.0 \pm 1.89$ & $63.0 \pm 1.15$ & $77.0 \pm 6.58$ & $62.0 \pm 1.78$ & $74.0 \pm 3.37$ & $94.0 \pm 8.36$ & $116 \pm 12.7$ & $107 \pm 3.40$ \\
\hline $\mathrm{CtBMD}\left(\mathrm{mg} / \mathrm{cm}^{3}\right)$ & $922 \pm 11.4$ & $917 \pm 6.40$ & $920 \pm 20.0$ & $951 \pm 11.6$ & $952 \pm 13.3$ & $912 \pm 25.0$ & $965 \pm 11.7$ & $929 \pm 6.40$ & $993 \pm 7.60$ \\
\hline $\mathrm{CtBMC}(\mathrm{mg} / \mathrm{mm})$ & $49.0 \pm 2.04$ & $42.0 \pm 0.57$ & $50.0 \pm 2.92$ & $65.0 \pm 9.02$ & $48.0 \pm 1.64$ & $59.0 \pm 3.86$ & $78.0 \pm 7.66^{\mathrm{a}}$ & $93.0 \pm 10.5^{\mathrm{b}}$ & $89.0 \pm 1.04^{b}$ \\
\hline $\mathrm{tA}\left(\mathrm{mm}^{2}\right)$ & $107 \pm 5.82$ & $87.0 \pm 0.29$ & $110 \pm 6.49$ & $121 \pm 7.75$ & $104 \pm 3.57$ & $130 \pm 8.55$ & $161 \pm 11.5^{\mathrm{a}}$ & $211 \pm 14.6^{\mathrm{b}}$ & $194 \pm 12.6^{\mathrm{b}}$ \\
\hline $\mathrm{CtA}\left(\mathrm{mm}^{2}\right)$ & $53.0 \pm 2.03$ & $46.0 \pm 0.31$ & $55.0 \pm 1.96$ & $68.0 \pm 10.3$ & $50.0 \pm 1.38$ & $64.0 \pm 2.64$ & $81.0 \pm 7.64^{\mathrm{a}}$ & $101 \pm 11.7^{b}$ & $89.2 \pm 0,49$ \\
\hline $\mathrm{CtT}(\mathrm{mm})$ & $1.69 \pm 0.09$ & $1.63 \pm 0.02$ & $1.72 \pm 0.14$ & $2.09 \pm 0.29$ & $1.62 \pm 0.08$ & $1.86 \pm 0.13$ & $2.11 \pm 0.16^{\mathrm{a}}$ & $2.67 \pm 0.20^{\mathrm{b}}$ & $2.09 \pm 0.10^{\mathrm{a}}$ \\
\hline PERI.C (mm) & $37.0 \pm 0.09$ & $33.0 \pm 0.05$ & $37.0 \pm 0.05$ & $39.0 \pm 1.24$ & $36.0 \pm 0.62$ & $40.0 \pm 1.31$ & $45.0 \pm 1.57^{\mathrm{a}}$ & $51.0 \pm 1.77^{\mathrm{b}}$ & $49.0 \pm 1.6^{\mathrm{ab}}$ \\
\hline ENDO.C (mm) & $26.0 \pm 1.36$ & $23.0 \pm 0.16$ & $26.0 \pm 2.01$ & $26.0 \pm 0.66$ & $26.0 \pm 0.87$ & $29.0 \pm 1.90$ & $32.0 \pm 1.06^{\mathrm{a}}$ & $37.0 \pm 0.56^{\mathrm{b}}$ & $36.0 \pm 2.24^{b}$ \\
\hline BSI $\left(\mathrm{mm}^{4} \cdot \mathrm{g} / \mathrm{cm}^{3}\right)$ & $141 \pm 7.20$ & $106 \pm 0.60$ & $147 \pm 6.10$ & $196 \pm 28.4$ & $140 \pm 5.40$ & $192 \pm 12.3$ & $294 \pm 37.7^{\mathrm{a}}$ & $404 \pm 35.8^{\mathrm{b}}$ & $362 \pm 18.9^{\mathrm{ab}}$ \\
\hline \multicolumn{10}{|l|}{ Metaphysis } \\
\hline $\mathrm{tBMD}\left(\mathrm{mg} / \mathrm{cm}^{3}\right)$ & $342 \pm 12.4$ & $276 \pm 15.8$ & $345 \pm 5.90$ & $299 \pm 23.5$ & $311 \pm 0.60$ & $247 \pm 12.1$ & $261 \pm 12.0$ & $274 \pm 12.5$ & $271 \pm 5.40$ \\
\hline $\mathrm{tBMC}(\mathrm{mg} / \mathrm{mm})$ & $91.0 \pm 3.70$ & $89.0 \pm 0.60$ & $85.0 \pm 3.60$ & $107 \pm 9.60$ & $129 \pm 16.5$ & $109 \pm 4.40$ & $153 \pm 9.90$ & $152 \pm 10.6$ & $139 \pm 9.40$ \\
\hline $\mathrm{tA}\left(\mathrm{mm}^{2}\right)$ & $265 \pm 13.5$ & $323 \pm 20.6$ & $247 \pm 6.10$ & $364 \pm 49.6$ & $416 \pm 52.4$ & $442 \pm 40.1$ & $588 \pm 48.1$ & $555 \pm 14.1$ & $511 \pm 24.4$ \\
\hline $\operatorname{TbBMD}\left(\mathrm{mg} / \mathrm{cm}^{3}\right)$ & $181 \pm 15.1$ & $184 \pm 8.70$ & $182 \pm 14.3$ & $174 \pm 12.6^{\mathrm{a}}$ & $223 \pm 6.70^{\mathrm{b}}$ & $165 \pm 8.70^{\mathrm{a}}$ & $152 \pm 12.9$ & $158 \pm 10.7$ & $145 \pm 6.40$ \\
\hline TbBMC (mg) & $22.0 \pm 1.68$ & $27.0 \pm 0.37$ & $20.0 \pm 2.04$ & $28.0 \pm 4.09^{\mathrm{a}}$ & $42.0 \pm 6.63^{\mathrm{b}}$ & $32.0 \pm 1.06^{\mathrm{a}}$ & $40.0 \pm 4.95$ & $40.0 \pm 3.64$ & $33.0 \pm 3.01$ \\
\hline $\mathrm{TbA}\left(\mathrm{mm}^{2}\right)$ & $119 \pm 6.10$ & $145 \pm 8.80$ & $111 \pm 2.60$ & $164 \pm 21.9$ & $186 \pm 23.4$ & $198 \pm 17.5$ & $264 \pm 21.1$ & $251 \pm 6.40$ & $230 \pm 10.6$ \\
\hline
\end{tabular}

a, b - means in rows with different superscripts differ significantly at the respective pig's age, $\mathrm{P}<0.05$; tBMD - total bone mineral density, tBMC total bone mineral content, CtBMD - cortical bone density, CtBMC - cortical bone mineral content, tA - total bone area, CtA - cortical area, CtT cortical thickness, PERI.C - periosteal circumference, ENDO.C - endosteal circumference, BSI - bone strength index, TbA - trabecular area, TbBMD - trabecular bone density, TbBMC - trabecular bone mineral content

\section{Discussion}

Recently, sodium butyrate and Yucca schidigera have received considerable attention, but most of the studies examined their influence on growth performance and the structure, function, and microbiology of the digestive tract $(10,12,14,16,19)$. The majority of research on Yucca schidigera has been focused on odour elimination in animal production (1). Although other properties of the bioactive substances found in the Yucca schidigera extract were shown to have an impact on the skeletal system (2), their combined effects with sodium butyrate have never been investigated so far. Thus, our research is the first in this field. The results of the present study indicate beneficial effects of diets on bone quality in growing piglets; however, significant differences were observed mainly in 56-day-old pigs. These results are consistent with our earlier findings (26). The higher values of mechanical parameters, such as ultimate strength and bone strength index, observed in both experimental groups, indicate an increase of bone resistance to dynamic loading force. Unfortunately, in the current literature there is no information about the influence of sodium butyrate and Yucca schidigera extract on bone quality in vivo.

The mechanical resistance depends on the amount and quality of bone tissue. Furthermore, bone geometry, trabecular bone composition, and microarchitecture are also important determinants of bone strength (37). DXA measurements clearly proved that sodium butyrate and Yucca schidigera extract supplementation increased bone mineral density and bone mineral content in both experimental groups. In this study, the values of geometric parameters, such as second moment of inertia and cross-sectional area, were higher in experimental pigs. Tomographic measurements also proved that sodium butyrate and Yucca schidigera influenced bone geometry. The values of diaphyseal tA, CtA, PERI.C, and ENDO.C increased after dietary supplementation. Moreover, our results indicate that experimental feeding accelerates endocortical resorption of bone tissue, causing an increase in medullary cavity volume and simultaneous increase in bone metabolism on pericortical surface. However, the relationship between ENDO.C and PERI.C did not influence the cortical thickness. We observed few significant differences between experimental groups, and these changes did not reveal special characteristics.

The bone status is related to the gastrointestinal tract. Changes in morphology and physiology of the gastrointestinal tract had influence on metabolism and parameters of bones $(4,9)$. Several studies have proved that the supplementation of diets with butyrate has beneficial effects on performance and digestive tract 
health in weaning pigs $(5,10,14,32,34)$. However, Tonel et al. (29) reported that a diet with butyrate had little effects on intestinal mucosa morphology of piglets. Butyrate has been shown to provide an important energy substrate for intestinal cells (8) and inhibit mucosal apoptosis (21). These results indicate that sodium butyrate plays an important role in maintaining the integrity of intestinal mucosa and may reduce some of the adverse effects of weaning stress. The improvement in intestinal environment is beneficial for the nutrient absorption. Sodium butyrate treatment improves digestive and absorptive capacities, and in this way it may probably influence the supply of nutrients for proper bone metabolism and bone features.

Moreover, a possible mechanism of sodium butyrate action may include the nuclear factor $\kappa \mathrm{B}(\mathrm{NF}$ $\kappa B)$ pathway. Studies have reported that butyrate can modulate the activity of the transcription factor NF- $\kappa \mathrm{B}$ in a number of different cell types $(27,34)$. Wen et al. (34) noted that sodium butyrate might show a positive effect on the gastrointestinal tract in weaning pigs through the pathway of decreasing the TNF- $\alpha$ and IL-6 levels in serum and inhibition of DNA-binding activity of the intestinal NF- $\kappa$ B. The TNF- $\alpha$ and IL- 6 are inflammatory cytokines, which also exert stimulating influence on osteoclastogenesis and osteoclasts activity. The positive effect on bones may results from decreasing the levels of TNF- $\alpha$ and IL- 6 . This is in line with the study of Weber and Kerr (35), who concluded that sodium butyrate may regulate the response to inflammatory stimuli in weaning pigs challenged with Escherichia coli lipopolysaccharide.

The receptor activator of NF- $\kappa B$ ligand (RANKL), a membrane-bound member of the TNF family, is essential for osteoclast differentiation. Via this ligand, receptor activator of $\mathrm{NF}-\mathrm{\kappa B}$ (RANK), located on the osteoclast progenitor cells, stimulates the signalling pathway regulating osteoclastogenesis. The osteoprotegerin (OPG) is a soluble decoy receptor that inhibits osteoclast differentiation through its binding to RANKL (11). A disturbance in the RANKL/OPG ratio results in an imbalance between osteoblastic and osteoclastic functions, and leads to the development of skeletal abnormalities. Sodium butyrate increased the expression of RANKL, decreased expression of OPG, and increased the ratio of RANKL/OPG through an ERK-dependent mechanism (3). The results of Chen et al. (3) suggest that sodium butyrate plays an important role in regulating the cell differentiation of multipotent mesenchymal stem cells (MSCs) and controls the ability of MSCs to induce osteoclast differentiation. The activation of NF- $\kappa \mathrm{B}$ and MAPKs pathways is thought to be critical in osteoclast differentiation $(13,18)$; thus if sodium butyrate exerts its effects through these pathways, it may act as a modulator of bone tissue homeostasis. On the other hand, sodium butyrate may inhibit the formation of preosteoclast-like cells and multinucleated osteoclast- like cells in rat bone marrow culture (27). Moreover, butyrate incorporated into small molecules, e.g. $\alpha$-calcium sulfate, improves osteoblast differentiation and pro-angiogenic responses, and in consequence stimulates bone regeneration (36).

The positive effect of the experimental diet on bone quality, which was observed in our study, may also partially result from the activity of the Yucca schidigera extract. Yucca contains anti-inflammatory polyphenolics, such as resveratrol and yuccaols A, B, C, D, and E $(23,25)$. Yuccaols potentially show the anti-inflammatory action due to their property to inhibit inducible nitric oxide synthase (iNOS) expression (17). In response to inflammatory mediators, iNOS-derived nitric oxide activates osteoclasts and may enhance bone resorption (31). The expression of iNOS is controlled by NF- $\kappa \mathrm{B}$ (31). Resveratrol and yucca phenolics

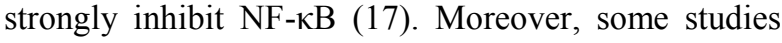
have demonstrated that saponins extracted from Yucca schidigera can also improve the absorption of nutrients by the intestinal mucosa surface (19).

To summarise, this study proved that simultaneous dietary supplementation with sodium butyrate and Yucca schidigera extract exerts a positive effect on bone quality in pigs in post-weaning period. However, whether $0.2 \%$ or $0.3 \%$ supplementation was applied, the difference in the influence on bone tissue was not marked. Nevertheless, the mechanism by which sodium butyrate and Yucca schidigera extract affect bone tissue is probably multidirectional, and our observations may only indirectly support possible explanation for the pathway action.

Conflict of Interests Statement: The authors declare that there is no conflict of interests regarding the publication of this article.

Financial Disclosure Statement: This research was supported from the funds of the Ministry of Science and Higher Education of the Republic of Poland.

Animal Rights Statement: The experimental procedures used throughout this study were approved by the $2^{\text {nd }}$ Local Ethics Committee on Animal Experimentation at University of Life Sciences in Lublin, Poland.

\section{References}

1. Cheeke P.R.: Actual and potential applications of Yucca schidigera and Quillaja saponaria saponins in human and animal nutrition. J Anim Sci 2000, 77, 1-10.

2. Cheeke P.R., Piacente S., Oleszek W.: Anti-inflammatory and anti-arthritic effects of yucca schidigera: A review. J Inflam 2006, 3, 6-12.

3. Chen T.H., Chen W.M., Hsu K.H., Kuo Ch.D., Hung S.Ch.: Sodium butyrate activates ERK to regulate differentiation of mesenchymal stem cells. Bioch Bioph Res Comm 2007, 355, 913-918. 
4. Chen D., Zhao C.M.: The possible existence of a gut-bone axis suggested by studies of genetically manipulated mouse models? Curr Pharm Des 2011, 17, 1552-1555.

5. Fang C.L., Sun H., Wu J., Niu H.H., Feng J.: Effects of sodium butyrate on growth performance, haematological and immunological characteristics of weanling piglets. J Anim Phys Anim Nutr 2014, 98, 680-685.

6. Ferretti J.L., Capozza R.F., Mondelo N., Montuori E., Zanchetta J.R.: Interrelationships between densitometric, geometric and mechanical properties of rat femora: inferences concerning mechanical regulation of bone modeling. J Bone Min Res 1993, 8, 1389-1395.

7. Holtug K., Rasmussen H.S., Mortensen P.B.: An in vitro study of short-chain fatty acid concentrations, production, and absorption in pig (Sus scrofa) colon. Comp Biochem Physiol 1992, 103A, 189-197.

8. Jozefiak. D., Rutkowski A., Martin S.A.: Carbohydrate fermentation in the avian ceca: a review. Anim Feed Sci Technol 2004, 113, 1-15.

9. Karsenty G., Gershon M.D.: The importance of the gastrointestinal tract in the control of bone mass accrual. Gastroenterology 2011, 141, 439-442.

10. Kotunia A., Wolinski J., Laubitz D., Jurkowska M., Rome V., Guilloteau P., Zabielski R.: Effect of sodium butyrate on the small intestine development in neonatal piglets feed by artificial sow. J Physiol Pharmacol 2004, 55, 59-68.

11. Lacey D.L., Timms E., Tan H.L., Kelley M.J., Dunstan C.R., Burgess T., Elliott R., Colombero A., Elliott G., Scully S., Hsu H., Sullivan J., Hawkins N., Davy E., Capparelli C., Eli A., Qian Y.X., Kaufman S., Sarosi I., Shalhoub V., Senaldi G., Guo J., Delaney J., Boyle W.J.: Osteoprotegerin ligand is a cytokine that regulates osteoclast differentiation and activation. Cell 1998, 93, 165-176.

12. Le Gall M., Gallois M., Seve B., Louveau I., Holst J.J., Oswald I.P., Lalles J.P. Guilloteau P.: Comparative effect of orally administered sodium butyrate before or after weaning on growth and several indices of gastrointestinal biology of piglets. Br J Nutr 2009, 102, 1285-1296.

13. Lee S.E., Woo K.M., Kim S.Y., Kim H.M., Kwack K., Lee Z. H., Kim H.-H.: The phosphatidylinositol 3-kinase, p38, and extracellular signal regulated kinase pathways are involved in osteoclast differentiation. Bone 2002, 30, 71-77.

14. Lu J.J., Zou X.T., Wang Y.M.: Effects of sodium butyrate on the growth performance, intestinal microflora and morphology of weanling pigs. J Anim Feed Sci 2008, 17, 568-578.

15. Lutz T., Scharrer E.: Effect of short-chain fatty acids on calcium absorption by the rat colon. Exp Physiol 1991, 76, 615-618.

16. Manzanilla E.G., Perez J., Martin M., Kamel C., Baucells F., Gasa J.: Effect of plant extracts and formic acid on the intestinal equilibrium of early-weaned pigs. J Anim Sci 2004, 82, 3210-3218.

17. Marzocco S., Piacente S., Pizza C., Oleszek W., Stochmal A., Pinto A., Sorrentino R., Autore G.: Inhibition of inducible nitric oxide synthase expression by yuccaol C from Yucca schidigera roezl. Life Sci 2004, 75, 1491-1501.

18. Matsumoto M., Sudo T., Saito T., Osada H., Tsujimoto M.: Involvement of p38 mitogen-activated protein kinase signaling pathway in osteoclastogenesis mediated by receptor activator of NF-kB ligand (RANKL). J Biol Chem 2000, 275, 31155-31161.

19. McAllister T.A., Wang Y., Hristov A.N., Olson M.E., Cheeke P.R.: Applications of Yucca schidigera in livestock production. In: Proc. 33 rd. Pac. Northwest Anim. Nutr. Conf., Vancouver, Canada, 1998, pp. 109-119.

20. McAllister T.A., Annett C.B., Cockwill C.L., Olson M.E., Yang Y., Cheeke P.R.: Studies on the use of Yucca schidigera to control giardiasis. Vet Parasit 2001, 97, 85-99.

21. Mentschel J., Claus R.: Increased butyrate formation in the pig colon by feeding raw potato starch leads to a reduction of colonocyte apoptosis and a shift to the stem cell compartment. Metabolism 2003, 52, 1400-1405.
22. Mroz Z., Jongbloed A.W., Partanen K.H., Vreman K., Kemme P.A., Kogut J.: The effects of calcium benzoate in diets with or without organic acids on dietary buffering capacity, apparent digestibility, retention of nutrients, and manure characteristics in swine. J Anim Sci 2000, 78, 2622-2632.

23. Oleszek W., Sitek M., Stochmal A., Piacente S., Pizza C., Cheeke P.: Resveratrol and other phenolics from the bark of Yucca schidigera Roezl. J Agric Food Chem 2001, 49, 747-752.

24. Perrin P., Pierre F., Patry Y., Champ M., Berreur M., Pradal G., Bornet F., Meflah K., Menanteau J.: Only fibres promoting a stable butyrate producing colonic ecosystem decrease the rate of aberrant crypt foci in rats. Gut 2001, 48, 53-61.

25. Piacente S., Montoro P., Oleszek W., Pizza C.: Yucca schidigera bark: Phenolic constituents and antioxidant activity. J Nat Prod 2004, 67, 882-885.

26. Puzio I., Valverde Piedra J.L., Kapica M., Bieńko M., Pawłowska M., Kusińska E., Szymanczyk S.E.: The effect of butyrate and Yucca schidigera extract on bone quality in developing piglets. Krmiva 2008, 50, 329-333.

27. Rahman M., Kukita A., Kukita T., Shobuike T., Nakamura T., Kohashi O.: Two histone deacetylase inhibitors, trichostatin A and sodium butyrate, suppress differentiation into osteoclasts but not into macrophages. Blood 2003, 101, 3451-3459.

28. Świątkiewicz S., Arczewska-Wlosek A.: Bone quality characteristics and performance in broiler chickens fed diets supplemented with organic acids. Czech J Anim Sci 2012, 57, 193-205.

29. Tonel I., Pinho M., Lordelo M.M., Cunha L.F., Garres P., Freire J.P.B.: Effect of butyrate on gut development and intestinal mucosa morphology of piglets. Live Sci 2010, 133, 222-224.

30. Valverde Piedra J.L., Szymanczyk S.E., Kapica M., Puzio I., Pawlowska M., Michalowski P.: Combined effect of butyrate and Yucca schidigera extract on the gastrointestinal tract of pigs around weaning. Krmiva 2009, 51, 11-18.

31. Van't Hof R. J., Armour K. J., Smith L. M., K. E. Armour K. E., Wei X. Q., Liew F. Y., Ralston S. H. : Requirement of the inducible nitric oxide synthase pathway for IL-1-induced osteoclastic bone resorption. Proc Natl Sci USA 2000, 97, 7993-7998.

32. Wang J.F., Chen X., Wang Z.X., Dong S.H., Lai Z.W.: Effect of sodium butyrate on the structure of the small intestine mucous epithelium of weaning piglets. Chin J Vet Sci Technol 2005, 35, 298-301.

33. Wang J.P., Kim I.H.: Effect of caprylic acid and Yucca schidigera extract on production performance, egg quality, blood characteristics, and excreta microflora in laying hens. Br Poult Sci 2012, 52, 711-717.

34. Wen Z.S., Lu J.J., Zou X.T.: Effects of sodium butyrate on the intestinal morphology and DNA-binding activity of intestine nuclear factor- $\mathrm{\kappa B}$ in weanling pigs. J Anim Vet Adv 2012, 11, 814-821.

35. Weber T.E., Kerr B.J.: Effect of sodium butyrate on growth performance and response to lipopolysaccharide in weanling pigs. J Anim Sci 2008, 86, 442-450.

36. Woo K.M., Jung H.-M., Oh J.-H., Rahman S., Kim S.M., Baek J.-H., Ryoo H.-M.: Synergistic effects of dimethyloxalylglycine and butyrate incorporated into $\alpha$-calcium sulfate on bone regeneration. Biomaterials 2015, 39, 1-14.

37. Wu D., Li X., Tao Ch., Dai R., Ni J., Liao E.: Association of microstructural and mechanical properties of cancellous bone and their fracture risk assessment tool scores. Int J Clin Exp Med 2015, 8, 3956-3964.

38. Young G. P., Gibson P. R.: Butyrate and the human cancer cell. In: Physiological and Clinical Aspects of Short-Chain Fatty Acids, edited by Cummings J.H., Rombeau J.L., Sakata T., Cambridge University Press, Cambridge, UK, 1995, pp. 319-335. 